\title{
Antibiotic Prescribing for Acute Respiratory Tract Infections 12 Months After Communication and CRP Training: A Randomized Trial
}

\author{
Paul Little, MBBS, FRCGP \\ Beth Stuart, $P b D$ \\ Nick Francis, PbD \\ Elaine Douglas, PbD \\ Sarab Tonkin-Crine, $P b D$ \\ Sibyl Antbierens, MA, PbD \\ Jochen W.L. Cals, MD, PbD \\ Hasse Melbye, $\mathrm{PbD}$ \\ Miriam Santer, PbD \\ Michael Moore, FRCGP \\ Samuel Coenen, PbD \\ Chris C. Butler, FRCGP \\ Kerenza Hood, PbD \\ Mark Kelson, $\mathrm{PbD}$ \\ Maciek Godycki-Cwirko, MD, PbD \\ Artur Mierzecki, PbD \\ Antoni Torres, $\mathrm{PbD}$ \\ Carl Llor, $\mathrm{PbD}$ \\ Melanie Davies, BSc \\ Mark Mullee, MSc \\ Gilly O'Reilly, PbD \\ Alike van der Velden, $P b D$ \\ Adam W.A. Geraghty, PbD \\ Herman Goossens, PbD \\ Theo Verbeij, PbD, MRCGP \\ Lucy Yardley, PbD, on bebalf of the \\ GRACE consortium
}

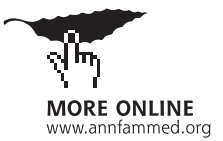

Conflicts of interest: autbors report none.

\section{CORRESPONDING AUTHOR}

Paul Little, MBBS, FRCGP

University of Southampton

Aldermoor Health Centre

Aldermoor Close

Southampton, SO16 5ST, United Kingdom p.little@soton.ac.uk

\begin{abstract}
PURPOSE C-reactive-protein (CRP) is useful for diagnosis of lower respiratory tract infections (RTIs). A large international trial documented that Internet-based training in CRP point-of-care testing, in enhanced communication skills, or both reduced antibiotic prescribing at 3 months, with risk ratios (RRs) of $0.68,0.53$, 0.38 , respectively. We report the longer-term impact in this trial.
\end{abstract}

METHODS A total of 246 general practices in 6 countries were cluster-randomized to usual care, Internet-based training on CRP point-of-care testing, Internetbased training on enhanced communication skills and interactive booklet, or both interventions combined. The main outcome was antibiotic prescribing for RTIs after 12 months.

RESULTS Of 228 practices providing 3-month data, 74\% provided 12-month data, with no demonstrable attrition bias. Between 3 months and 12 months, prescribing for RTIs decreased with usual care (from $58 \%$ to $51 \%$ ), but increased with CRP training (from 35\% to 43\%) and with both interventions combined (from 32\% to $45 \%)$; at 12 months, the adjusted RRs compared with usual care were 0.75 (95\% $\mathrm{Cl}, 0.51-1.00)$ and $0.70(95 \% \mathrm{Cl}, 0.49-0.93)$, respectively. Between 3 months and 12 months, the reduction in prescribing with communication training was maintained (41\% and 40\%, with an RR at 12 months of 0.70 [95\% Cl, 0.49-0.94]). Although materials were provided for free, clinicians seldom used booklets and rarely used CRP point-of-care testing. Communication training, but not CRP training, remained efficacious for reducing prescribing for lower RTIs (RR $=0.7195 \%$ $\mathrm{Cl}, 0.45-0.99$, and $\mathrm{RR}=0.76 ; 95 \% \mathrm{Cl}, 0.47-1.06$, respectively), whereas both remained efficacious for reducing prescribing for upper $\mathrm{RTIS}(\mathrm{RR}=0.60 ; 95 \% \mathrm{Cl}$, $0.37-0.94$, and $\mathrm{RR}=0.58 ; 95 \% \mathrm{Cl}, 0.36-0.92$, respectively).

CONCLUSIONS Internet-based training in enhanced communication skills remains effective in the longer term for reducing antibiotic prescribing. The early improvement seen with CRP training wanes, and this training becomes ineffective for lower RTIs, the only current indication for using CRP testing.

Ann Fam Med 2019;17:125-132. https://doi.org/10.1370/afm.2356.

\section{INTRODUCTION}

$\Lambda$ cute uncomplicated lower respiratory tract infections (LRTIs) and upper respiratory tract infections (URTIs) are the leading acute presentations in primary care, and most patients still receive antibiotics $^{1-4}$ despite evidence of limited benefit. ${ }^{4-6}$ Antibiotic resistance is a major public health threat, and primary care prescribing has a key role. ${ }^{7}$

Educational outreach and training in enhanced communication skills for clinicians to explore patients' concerns can reduce antibiotic prescribing. ${ }^{8-13}$ Particular concerns for clinicians and patients are complications such as pneumonia ${ }^{14,15} ;$ here, $\mathrm{C}$-reactive protein $(\mathrm{CRP})$ point-of-care tests have utility for diagnosing LRTI.$^{16}$ Physician training on use of these tests reduces antibiotic prescribing by approximately $20 \%$ in the short term, ${ }_{1}^{8,9}$ so several guidelines now advocate use of CRP in this context. ${ }^{17-19}$ 
Evidence for education outreach mostly documents highly expert teams helping a small number of practices, limiting generalizability of these interventions. A large pan-European trial, however, documented the impact of brief Internet-based physician training on use of a CRP point-of-care test and on enhanced communication skills using an interactive patient booklet. In the communication group, there was a clinically unimportant increase in symptom duration (a secondary outcome) of 1 day, but both interventions reduced antibiotic prescribing (the primary outcome) by 3 months, with risk ratios (RRs) of 0.53 and 0.68 , respectively, and even greater benefit seen with their combination, with an RR of $0.38 .{ }^{20}$ Communication training was the most cost-effective intervention. ${ }^{21}$ It is unclear whether either of these brief interventions has longerlasting effects on antibiotic use, which is vital to curb the emergence of antibiotic resistance. We report the impact of the interventions after 12 months.

\section{METHODS}

The methods of this trial are given in greater detail elsewhere ${ }^{20}$; a summary is given below. Ethical approval in the United Kingdom was granted by Southampton and South West Hampshire Local Research Ethics Committee for Genomics to combat Resistance against Antibiotics for Community-acquired LRTI in Europe: INternet Training for Reducing antibiOtic use trial (short title: GRACE INTRO Trial, REC Ref 10/H0502/29). The research sites outside of the United Kingdom also obtained ethical approval from their local organizations.

Patients who met the trial's inclusion criteria were given written and verbal information about the study and asked for informed consent. There was no individual-level consent for data collection at 12 months.

\section{Trial Design and Audits}

We chose a cluster design to minimize contamination within practices. The 4 randomization groups facilitated both $2 \times 2$ factorial analysis and individual group analysis.

The second audit to assess antibiotic prescribing was added after the trial began. As funding for the trial was uncertain, we asked participating clinicians for the 12 -month audit only after they had completed the 3 -month audit. Clinical outcomes other than prescribing were not assessed at 12 months because of resource limitations as well as the finding of minimal impact of the interventions on these outcomes at 3 months.$^{16}$ For example, at 3 months, there were no significant differences between groups (described below) in hospital admissions, with 2 to 12 admissions per group, and most due to cardiorespiratory or systemic causes (eg, high fever).

\section{Participants and Timeline}

Eight primary care research networks invited local general practices to participate in the trial. The networks covered a range of countries, and their diverse health systems, languages, and cultures: England (Southampton), Wales (Cardiff), the Netherlands (Utrecht), Belgium (Antwerp), Poland (Łódź; Szczecin), and Spain (Barcelona; semFYC). Within each practice, all clinicians who prescribed antibiotics for RTI could participate (including some UK nurse prescribers).

The trial timeline began at baseline with an audit of consecutive participants to document usual prescribing practices, conducted between October and December 2010. At the 3-month audit (February-May 2011), ${ }_{1}^{20}$ clinicians were asked to recruit 30 consecutive patients with LRTI (the main intervention target population) and 5 with URTI. At the 12-month audit (October 2011-May 2012), because the interventions had been found efficacious for both LRTI and URTI at 3 months, ${ }^{20}$ both conditions were assessed with no instructions to clinicians to preferentially recruit patients with LRTI.

\section{Inclusion Criteria}

Included practices were required to have had no prior participation in antibiotic stewardship interventions and to be able to recruit more than 10 patients at baseline.

Included patients were adults (aged 18 years or older) with LRTI or URTI. We defined LRTI as up to 28 days of cough as the most prominent symptom, or if not (eg, chills most prominent), the clinician judged the condition to be LRTI. Patients with pneumonia and chronic airway disease were included because their management could have been modified by the interventions. URTI was defined as clinician-judged other RTI (sore throat, otitis media, sinusitis, influenza, coryzal illness, or some combination thereof). Patients were excluded if they had a noninfective diagnosis (eg pulmonary embolus), had recently received antibiotics (within the previous 28 days), were unable to provide informed consent (eg, because of dementia), were pregnant, or had immune deficiencies.

\section{Randomization, Arms, and Interventions}

Practices were remotely randomized using the minimization approach, based on practice characteristics (baseline prescribing, number of clinicians, number of patients at baseline) and with stratification by network. The 2 interventions, communication training and CRP training, were developed to be sensitive to cultural differences ${ }^{22}$ while retaining core features. Practices were randomized into 4 trial arms, as follows. 
In the usual care arm, no intervention was provided. In the CRP arm, practices were given Internet-based training on use of a CRP point-of-care test. The test device was demonstrated by company representatives; the Internet training provided guidance on CRP use (Supplemental Appendix 1, available at http://www. AnnFamMed.org/content/17/2/125/suppl/DC1/). The device and testing materials were provided free. In the communication arm, practices were given Internet-based training on enhanced communication skills and use of an interactive patient booklet (Supplemental Appendix 1) The training focused on interactive use of the booklet in consultations and enhanced patient-centered communication-eliciting concerns/expectations, exchanging information, agreeing on management, summing up, and applying safety-net methods-supported by short demonstration video clips. The booklet included information about causes of symptoms, natural history, antibiotics, self-help, and when to consult the practice again. Group practices appointed a lead physician to organize a structured meeting on prescribing. In the combined intervention arm, practices received both the CRP intervention and the communication intervention.

\section{Outcomes}

Clinicians used case report forms to document symptoms and signs, and illness duration; use of CRP and booklets; and antibiotic prescribing. The trial's primary outcome was antibiotic prescribing documented in the case report form by the recruiting clinician. Limited availability of prescription monitoring precluded use of pharmacy dispensing data.

\section{Sample Size and Analysis}

The sample size was calculated for an $\alpha$ of .025 and a $\beta$ of .2. We assumed that 30 patients per practice would be recruited, that a $50 \%$ to $40 \%$ reduction in antibiotic prescribing would be achieved for at least 1 of the interventions ${ }^{8,23}$; and that the intracluster correlation coefficient would range from $0.16^{8,24,25}$ to $0.06{ }^{26}$ We therefore required 2,600 patients (intracluster correlation coefficient $=0.06$ ) to 5,400 patients (intracluster correlation coefficient $=0.16$ ).

We used multilevel logistic regression modeling for a factorial study, controlling for baseline antibiotic prescribing rate, clustering by physician and practice, whether the patient had a URTI or LRTI, and a range of potential confounders. There was no additional effect of international network; hence, it was not included in models. We undertook a secondary analysis for the individual randomization groups because the study was not powered for interactions. The odds ratios were converted to RRs. ${ }^{27}$ Analysis was conducted on an intentionto-treat basis. To assess attrition bias (1) we used data aggregated at the practice level, and multiple imputation to impute data from practices that had not agreed to be followed up, and (2) we compared estimates at 3 months just for those practices followed up at 12 months.

\section{RESULTS}

\section{Participants and Follow-up}

At the baseline audit, 5,355 patients (79.1\%) had LRTI and 1,416 (20.9\%) had URTI. Overall, 3,742 (55\%) were prescribed antibiotics.

A total of 372 participating clinicians in 228 of 246 practices contributed data for 4,264 patients at the 3 -month follow-up (Figure 1), of whom 20\% had URTI. Of the 228 practices providing 3 -month data, $168(74 \%)$ provided 12 -month data. A total of 247 clinicians in these 168 practices contributed data for 4,830 patients at the 12 -month follow-up, of whom $41 \%$ had URTI ${ }_{i}$ hence, we controlled for URTI in the estimates.

The groups were well balanced at 3 months and remained so at 12 months (Table 1). Initial compliance with training was good, with most clinicians completing all modules: CRP, 99 of $113(88 \%)$; communication, 94 of $108(87 \%)$; and combination, 116 of $127(91 \%)$.

\section{Use of Study Materials}

By 12 months, clinicians in all groups had seldom used CRP testing in patient care, even though they were given free access to CRP diagnostic kits: usual care, 16 of 1,195 (1.34\%), CRP, 62 of 1,075 (5.77\%); communication, 56 of $1,168(4.79 \%)$; and combination, 85 of 1,419 (5.99\%). Booklets were used fairly sparingly too: communication, 189 of $1,186(16 \%)$ and combination, 340 of $1,428(24 \%)$.

\section{Efficacy of the Interventions}

\section{Factorial Analysis}

Results of factorial analysis showed that at 3 months, $48 \%$ (984 of 2,040) of the patients consulting clinicians who were not trained in using CRP were prescribed antibiotics, and by 12 months, the value was little changed, at $46 \%(1,078$ of 2,360$)$ (Table 2$)$. The antibiotic prescribing rate in the CRP groups was $33 \%$ (734 of 2,224$)$ at 3 months but $45 \%(1,097$ of 2,462$)$ at 12 months $_{i}$ however, the adjusted RR was a nonsignificant 0.87 compared with the no-training control at 12 months (95\% CI, 0.68-1.06; $P=.18$ ).

At 3 months, $45 \%$ (876 of 1,932$)$ of the patients consulting clinicians who were not trained in enhanced communication were prescribed antibiotics, and similarly, at 12 months, $48 \%(1,069$ of 2,246$)$ were. The antibiotic prescribing rate in the communications groups was $36 \%(842$ of 2,332$)$ at 3 months but $43 \%$ $(1,106$ of 2,576$)$ at 12 months; the adjusted RR com- 
pared with no training at 12 months was a significant $0.81(95 \% \mathrm{CI}, 0.64-1.00 ; P=.049)$.

\section{Analysis of Individual Groups}

The factorial analysis probably masks effectiveness of individual interventions because there was a sizable interaction term between the CRP and communication interventions $(1.67 ; P=.16)$. The individual group analysis yielded somewhat different results (Table 3 ).

Among patients receiving usual care, whose clinicians received no training, 58\% (508 of 870) were prescribed antibiotics at 3 months, and the value had decreased by an absolute $7 \%$, to $51 \%$ (613 of 1,194$)$, at 12 months in part due to more cases of URTI. Prescribing in the CRP group, however, rose by almost 9\% from 35\% (368 of 1,062 ) at 3 months to $43 \%$ (456 of 1,052 ) at 12 months (adjusted RR compared with usual care at 12 months $=0.75$; $95 \% \mathrm{CI}, 0.51-1.00 ; P=.052$ ). Similarly, among patients in the combined intervention group, $32 \%$ (476 of 1,170$)$ were prescribed antibiotics at 3 months, with an absolute $13 \%$ increase to $45 \%$ (641 of $1,410)$ at 12 months (adjusted RR compared with usual care at 12 months $=0.70 ; 95 \% \mathrm{CI}$,
$0.49-0.93 ; P=.01)$. Among those in the communication group, $41 \%$ (476 of 1,170$)$ were prescribed antibiotics at 3 months, with virtually no change by 12 months, $40 \%$ (465 of 1,166) (adjusted RR compared with usual care at 12 months $=0.70 ; 95 \% \mathrm{CI}, 0.49-0.94 ; P=.02)$.
Figure 1. CONSORT flow diagram.

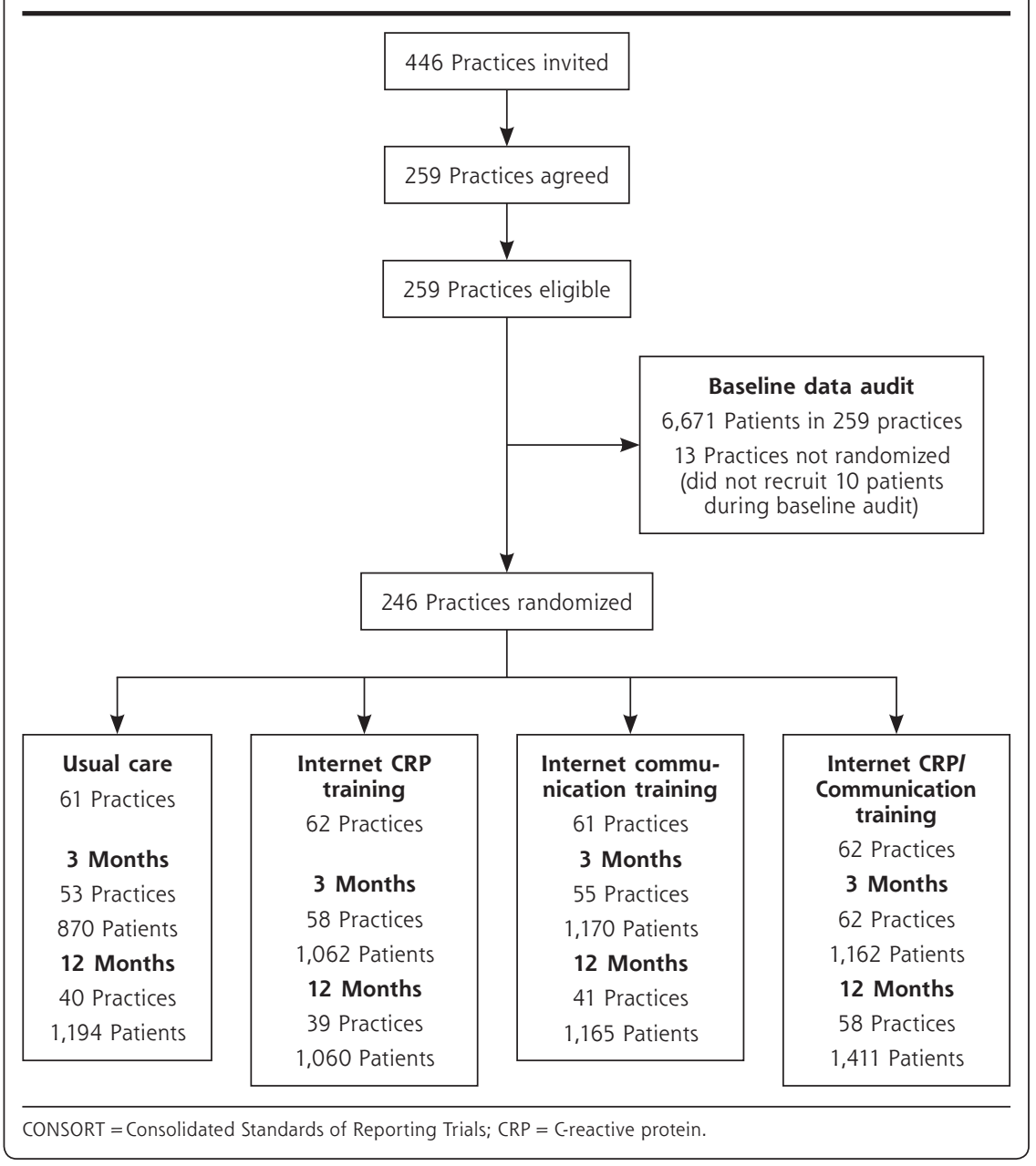

\section{Table 1. Patient Characteristics}

\begin{tabular}{|c|c|c|c|c|c|}
\hline \multirow[b]{3}{*}{ Characteristic } & \multirow[b]{3}{*}{$\begin{array}{c}\text { Baseline } \\
(n=6,771)\end{array}$} & \multicolumn{4}{|c|}{3 Months of Follow-up } \\
\hline & & \multicolumn{2}{|c|}{ CRP Training } & \multicolumn{2}{|c|}{ Communication Training } \\
\hline & & $\begin{array}{c}\text { Control } \\
(n=2,040)\end{array}$ & $\begin{array}{c}\text { Intervention } \\
(n=2,224)\end{array}$ & $\begin{array}{c}\text { Control } \\
(n=1,932)\end{array}$ & $\begin{array}{c}\text { Intervention } \\
(n=2,332)\end{array}$ \\
\hline Sex, female, No. (\%) & $4,218(62)$ & $1,311(64)$ & $1,423(64)$ & $1,223(63)$ & $1,511(65)$ \\
\hline Age, mean (SD), y & $49.6(18.6)$ & $50.9(17.3)$ & $51.0(17.5)$ & $50.8(17.6)$ & $51.1(17.2)$ \\
\hline Never-smoker, No. (\%) & N/A & $1,067(52)$ & $1,147(52)$ & $1,041(54)$ & $1,173(50)$ \\
\hline Illness duration before index consultation $\geq 5$ days, No. (\%) & $3,542(53)^{a}$ & $1,038(51)^{\mathrm{a}}$ & $1,128(51)^{\mathrm{a}}$ & $994(52)^{\mathrm{a}}$ & $1,172(51)^{\mathrm{a}}$ \\
\hline Respiratory rate $\geq 25$ breaths/minute, No. (\%) & N/A & $101(5)^{\mathrm{a}}$ & $123(6)^{a}$ & $145(8)^{\mathrm{a}}$ & $79(3)^{\mathrm{a}}$ \\
\hline Temperature $\geq 38^{\circ} \mathrm{C}$, No. (\%) & $\mathrm{N} / \mathrm{A}$ & $228(11)^{\mathrm{a}}$ & $280(13)^{\mathrm{a}}$ & $202(11)^{\mathrm{a}}$ & $306(13)^{\mathrm{a}}$ \\
\hline
\end{tabular}


Results differed somewhat by type of RTI. For patients with LRTI, communication was still effective compared with usual care at 12 months (adjusted $\mathrm{RR}=0.71 ; 95 \% \mathrm{CI}, 0.45-0.99)$, but CRP was not (adjusted $\mathrm{RR}=0.76 ; 95 \% \mathrm{CI}, 0.47-1.06$ ). For patients with URTI, benefit of both interventions relative to usual care was maintained at 12 months: communications (adjusted $\mathrm{RR}=0.60 ; 95 \% \mathrm{CI}, 0.37-0.94 ; P=.02$ ) and CRP (adjusted RR $=0.58 ; 95 \% \mathrm{CI}, 0.36-0.92$; $P=.02)$.

\section{Assessment of Attrition Bias}

Data from practices where follow-up was possible were comparable to those for the entire trial population (Supplemental Appendix 2, Supplemental Table 5, and Supplemental Table 6, available at http://www. AnnFamMed.org/content/17/2/125/suppl/DC1/). In our practice-level analysis, we compared results for the practices completing follow-up at 12 months with estimates for all practices that were derived with imputation for missing data (Table 4). Although the absolute estimates of efficacy differed slightly, with lower power and less robustness (because of inability to control for individual patient characteristics), there was no meaningful change in the practice-based estimates. This finding suggests that there was minimal attrition bias related to practices not completing the study.

As a further check, we determined that estimates at 3 months from completers were also very similar to results for the whole trial cohort. The RRs were 0.54 for CRP and 0.68 for communication among completers, and 0.54 and 0.69 , respectively, among the whole trial cohort.

\section{DISCUSSION}

As far as we are aware, this is the first major multicenter international trial to assess longer-term effec-

12 Months of Follow-up

\begin{tabular}{cccc}
\multicolumn{2}{c}{ CRP Training } & \multicolumn{2}{c}{ Communication Training } \\
$\begin{array}{c}\text { Control } \\
(\mathbf{n}=\mathbf{2}, \mathbf{4 6 3})\end{array}$ & $\begin{array}{c}\text { Intervention } \\
(\mathbf{n}=\mathbf{2 , 6 9 9 )}\end{array}$ & $\begin{array}{c}\text { Control } \\
(\mathbf{n}=\mathbf{2 , 4 6 4 )}\end{array}$ & $\begin{array}{c}\text { Intervention } \\
(\mathbf{n}=\mathbf{2 , 6 9 8})\end{array}$ \\
\hline $1,470(60)$ & $1,620(60)$ & $1,466(60)$ & $1,624(60)$ \\
$51.7(18.8)$ & $51.2(18.7)$ & $51.1(18.6)$ & $51.7(18.8)$ \\
$\mathrm{N} / \mathrm{A}$ & $\mathrm{N} / \mathrm{A}$ & $\mathrm{N} / \mathrm{A}$ & $\mathrm{N} / \mathrm{A}$ \\
$1,026(42)$ & $1,198(44)$ & $1,032(42)$ & $1,192(44)$ \\
$65(3)^{\mathrm{a}}$ & $133(5)$ & $96(4)$ & $102(4)$ \\
$291(12)$ & $380(14)$ & $285(12)$ & $386(14)$ \\
\hline
\end{tabular}

tiveness of Internet-based training to modify antibiotic prescribing for RTIs. Although antibiotic prescribing decreased with usual care during follow-up out to 12 months, communication training remained more efficacious at that time, whereas CRP training did not.

\section{Potential Limitations}

Our trial had a number of potential limitations. Practices were approached only after 3 months to request further follow-up, and $26 \%$ of those providing 3 -month data declined to continue. Baseline characteristics, however, were similar for practices that were not followed up, and the practice-level analysis using multiple imputation demonstrated no attrition bias. The majority of practices approached agreed, and many of them had not previously taken part in research.

As expected, clinicians reported struggling to document consecutive patients at busy times of year. But previous research has shown this challenge results in little selection bias, ${ }^{28,29}$ and there were minimal barriers to participation for the 12 -month audit (the trial used quick audit proformas, and there was no delay for patient consent). Antibiotic prescribing was similar to that seen in previous studies, ${ }^{2,4}$ and at baseline, the majority of patients in usual care received antibiotics, which suggests the trial's results are generalizable.

There was no evidence of differential selection bias comparing groups, and analysis controlled for differences in case mix. At 12 months, usual care prescribing had fallen slightly, by $7 \%$, perhaps because of pressure on clinicians (eg, the European Antibiotic Awareness Day), but also, there were more patients with URTI at that time point, which explained onehalf the reduction. The findings cannot be explained by case mix, however, because we controlled for a range of variables in the analysis. We checked fidelity with initial training but did not observe actual consultations (to avoid influencing behavior). We did not record other clinical outcomes at 12 months given the modest impact seen at 3 months. ${ }^{20}$

\section{Comparison With Other Studies}

In this trial, the benefit of communication training was durable, supporting prior evidence for interactive methods. ${ }^{10,11}$ Our process evaluation also indicated that communication training promoted changes in physician attitudes that should be helpful in the longer term. ${ }^{22,30,31}$ The Stemming the Tide of Antibiotic Resistance (STAR) trial achieved a $4 \%$ reduction in overall antibiotic prescribing but was more intensive ( 5 online phases vs 1 in this study, plus expert-led outreach seminars)..$^{13}$ Our intervention yielded less initial reduction than the Dutch IMPAC3T trial, ${ }^{8}$ but that trial was also more intensive, with face-to-face com- 
Table 2. Factorial Analysis: Efficacy of Interventions in Reducing Antibiotic Prescribing at 12 Months

\begin{tabular}{|c|c|c|c|c|}
\hline Measure & $\begin{array}{l}\text { No CRP Training } \\
\quad(n=2,360)\end{array}$ & $\begin{array}{l}\text { CRP Training } \\
(n=2,462)\end{array}$ & $\begin{array}{l}\text { No Communication } \\
\text { Training }(n=2,246)\end{array}$ & $\begin{array}{c}\text { Communication } \\
\text { Training }(n=2,576)\end{array}$ \\
\hline Patients prescribed antibiotics, No. (\%) & $1,078(45.7)$ & $1,097(44.6)$ & $1,069(47.6)$ & $1,106(42.9)$ \\
\hline Basic risk ratio $(95 \% \mathrm{Cl})[\mathrm{P} \text { value }]^{\mathrm{a}}$ & ref & $0.91(0.77-1.05)[.22]$ & ref & $0.90(0.77-1.04)[.17]$ \\
\hline Fully adjusted risk ratio $(95 \% \mathrm{Cl})[P \text { value }]^{b}$ & ref & $0.87(0.68-1.06)[.18]$ & ref & $0.81(0.64-1.00)[.049]$ \\
\hline \multicolumn{5}{|l|}{$\mathrm{CRP}=\mathrm{C}$-reactive protein; ref = reference group. } \\
\hline \multicolumn{5}{|c|}{$\begin{array}{l}\text { a The basic model adjusted for baseline prescribing and clustering by physician and practice. } \\
\text { b The fully adjusted model controlled for diagnosis (lower respiratory tract infection, upper respiratory tract infection, pneumonia), sex, age, presence of cough, } \\
\text { phlegm, shortness of breath, blocked/runny nose, chest pain, fever, muscle ache, headache, disturbed sleep, feeling generally unwell, interference with social activities, } \\
\text { earache, sore throat, facial/sinus pain, crackles, wheeze, pulse }>100 \text { beats per minute, temperature }>37.8^{\circ} \mathrm{C} \text {, respiratory rate, physician's rating of severity, low blood } \\
\text { pressure, duration of cough, and duration of illness before consultation. }\end{array}$} \\
\hline
\end{tabular}

Table 3. Individual Group Analysis: Efficacy of Interventions in Reducing Antibiotic Prescribing at 12 Months

\begin{tabular}{|c|c|c|c|c|}
\hline Measure & $\begin{array}{l}\text { Usual Care } \\
(n=1,194)\end{array}$ & $\begin{array}{l}\text { CRP Training } \\
(n=1,052)\end{array}$ & $\begin{array}{c}\text { Communication } \\
\text { Training }(n=1,166)\end{array}$ & $\begin{array}{l}\text { Combination } \\
(n=1,410)\end{array}$ \\
\hline Patients prescribed antibiotics, No. (\%) & $613(51.3)$ & $456(43.4)$ & 465 (39.9) & $641(45.5)$ \\
\hline Basic risk ratio $(95 \% \mathrm{Cl})[P \text { value }]^{a}$ & ref & $0.83(0.66-1.02)[.08]$ & $0.83(0.66-1.01)[.07]$ & $0.83(0.66-1.00)[.053]$ \\
\hline Fully adjusted risk ratio $(95 \% \mathrm{CI})[\mathrm{P} \text { value }]^{\mathrm{b}}$ & ref & $0.75(0.51-1.00)[.052]$ & $0.70(0.49-0.94)[.02]$ & $0.70(0.49-0.93)[.01]$ \\
\hline
\end{tabular}

CRP = C-reactive protein; ref $=$ reference group.

a The basic model adjusted for baseline prescribing and clustering by physician and practice.

${ }^{\mathrm{b}}$ The fully adjusted model controlled for the variables listed under Table 1.

Table 4. Assessment of Attrition Bias: Completing Practices and All Practices With Imputation

\begin{tabular}{|c|c|c|c|c|}
\hline Measure & Usual Care & CRP Training & Communication Training & Combination \\
\hline \multicolumn{5}{|c|}{ Practices completing 12 months of follow-up } \\
\hline Patients prescribed antibiotics, $\%$ & 51.0 & 42.9 & 39.8 & 47.1 \\
\hline Difference, $\%(95 \% \mathrm{Cl})[P \text { value }]^{\mathrm{a}}$ & ref & $-7(-15$ to 2$)[.11]$ & $-7(-15$ to 1$)[.09]$ & $-4(-12$ to 4$)[.30]$ \\
\hline \multicolumn{5}{|c|}{ All practices, with imputation for missing data } \\
\hline Patients prescribed antibiotics, $\%$ & 49.7 & 42.9 & 41.9 & 47.0 \\
\hline Difference, \% (95\% Cl) [P value $]^{a}$ & ref & $-6(-14$ to 3$)[.22]$ & $-7(-15$ to 1$)[.10]$ & $-4(-12$ to 4$)[.34]$ \\
\hline
\end{tabular}

$\mathrm{CRP}=\mathrm{C}$-reactive protein; ref $=$ reference group.

Note: A practice-level analysis.

a Reduction in proportion compared with usual care controlling for baseline prescribing and practice-level averages of patient characteristics: age, type of infection (lower respiratory tract infection vs upper respiratory tract infection), presence of symptoms (crackles, wheeze, pulse higher than 100 beats per minute, temperature higher than $37.8^{\circ} \mathrm{C}$ ), respiratory rate, physician's rating of severity, and duration of cough.

munication training. The long-term effect on behavior in our study was similar to that seen with other, more intensive interventions. ${ }^{8,13,32}$ Booklets were initially important, but their limited use in follow-up-despite the intervention's persistent efficacy-suggests that clinicians had consolidated skills and were being more selective in using this resource.

Communication was slightly less effective than CRP training or the combined intervention at 3 months (RRs $=0.68$ vs 0.53 and 0.38 , respectively), a finding comparable to the trend seen in the Dutch trials. ${ }^{8,9}$ Even though all materials were provided for free, CRP tests were little used by 12 months, and the effectiveness of CRP training had waned substantially (RRs $=0.70,0.75$, and 0.70, respectively) - but the diminished impact was particularly pronounced among patients with LRTI, where use of CRP to guide prescribing is supported. ${ }^{17-19}$ Our findings support long-term findings for LRTI from the smaller, intensive IMPAC3T trial, where there was no longer a significant effect of CRP training at follow-up, but the effect of communication training persisted. ${ }^{32}$ The waning in efficacy of CRP training may reflect the general waning of quality improvement interventions over time, although no similar effect occurred with communication training. It is unclear whether further reduction in the effi- 
cacy of CRP training would occur beyond 12 months. The logistics of providing this training and the time required to do the test at the busiest times of year may also be key disincentives to longer-term engagement.

The persistent benefit of CRP training in reducing antibiotic prescribing for URTI despite low use of CRP may be due to clinicians having learned to prescribe fewer antibiotics when using CRP, or to the training content for both CRP and communication, which shared introductory modules about the limited benefit of antibiotics, that is, that they have a nonspecific effect that is possibly unrelated to CRP per se. Ongoing incentives would probably be needed for clinicians to continue using CRP testing, but evidence of cost-effectiveness of this approach would be needed. As communication training was the most cost-effective option at 3 months when allowing for the costs of antibiotic resistance, ${ }^{21}$ its lasting impact makes it likely to be even more cost-effective.

\section{Conclusion}

Internet-based training in enhanced communication skills to reduce antibiotic prescribing for RTI remains efficacious in the longer term. In contrast, an early improvement with CRP training wanes over time, and this strategy becomes ineffective long term both overall and for LRTI, the only current indication for using CRP to guide decisions about antibiotic therapy. Our trial's findings suggest there is probably only short-term benefit from training clinicians in routine primary care to use CRP. Instead, the most useful training for long-lasting effects is likely in enhanced communication skills.

To read or post commentaries in response to this article, see it online at http://www.AnnFamMed.org/content/17/2/125.

Key words: antibiotics; prescribing; antimicrobial stewardship; respiratory tract infections; antimicrobial resistance; primary care; clinical practice patterns; communication; C-reactive protein; practice-based research

Submitted July 30, 2018; submitted, revised, December 10, 2018; accepted December 31, 2018.

Author affiliations: Primary Care and Population Sciences Unit, University of Southampton, Southampton, United Kingdom (Little, Mullee, Stuart, O'Reilly, Moore, Geraghty, Santer); School of Psychological Science, University of Bristol, Bristol, United Kingdom (Yardley); Economics Division, Stirling Management School, University of Stirling, Stirling, UK (Douglas); Julius Center for Health Sciences and Primary Care, University Medical Center Utrecht, Utrecht, The Netherlands (Verheij, van der Velden); Nuffield Department of Primary Care Health Sciences, University of Oxford, Oxford, United Kingdom (Butler, Tonkin-Crine); Division of Population Medicine, School of Medicine, Cardiff University, Cardiff, United Kingdom (Francis); South East Wales Trials Unit, Centre for Trials Research, Cardiff University, Cardiff, United Kingdom (Hood); Department of Mathematics, College of Engineering, Mathematics and Physical Sciences, University of Exeter, Exeter, UK (Kelson); Centre for Family and Community Medicine, Faculty of Health Sciences, Medical University of Łódź, Łódź, Poland (Godycki-Cwirko); Laboratory of Family
Physician Education, Pomeranian Medical University, Szczecin, Poland (Mierzecki); Ely Bridge Surgery, Ely, Cardiff, United Kingdom (Davies); Pneumology Department, Clinic Institute of Thorax (ICT), Hospital Clinic of Barcelona-Institut d'Investigacions Biomèdiques August Pi i Sunyer (IDIBAPS)-University of Barcelona (UB)-Ciber de Enfermedades Respiratorias (Ciberes) Villarroel, Barcelona, Spain (Torres); Department of Primary and Interdisciplinary Care (ELIZA), Department of Epidemiology and Social Medicine and Vaccine \& Infectious Disease Institute (VAXINFECTIO), University of Antwerp, Antwerp, Belgium (Coenen); Laboratory of Medical Microbiology, Vaccine $\varepsilon$ Infectious Disease Institute (VAXINFECTIO), University of Antwerp, Antwerp, Belgium (Goossens); Department of Primary and Interdisciplinary Care (ELIZA), University of Antwerp, Antwerp, Belgium (Anthierens); University Rovira i Virgili, Tarragona, Spain, Spanish Society of Family Medicine (semFYC) (Llor); Maastricht University/CAPHRI, Maastricht, The Netherlands (Cals); and General Practice Research Unit, Department of Community Medicine, UIT the Arctic University of Norway, Tromsø, Norway (Melbye).

Author contributions: The initial idea for this study was proposed by P.L., T.V., C.C.B, S.C., and H.G.; all authors contributed to the development of the protocol, and to the management of the study; G.O. and C.B. led the day-to-day management of the study supervised by P.L. and T.V., respectively; L.Y. led and supervised the design and development of the web-based intervention; L.Y., N.F., P.L., and C.C.B. led the development of the communication intervention. J.C., H.M., and P.L. led the development of the CRP intervention. Both interventions benefited from input of the network leads. Frank Leus supervised the web-based data management. H.G. led the funding application and provided overall coordination of the GRACE consortium; K.H. coordinated randomization, and M.K., P.L., B.S., and M. Mullee analyzed the data; all authors contributed to the interpretation of the data and the write-up. P.L., M. Mullee, and B.S. had full access to all of the data in the study and take responsibility for the integrity of the data and the accuracy of the data analysis.

Funding support: The research performed by the GRACE (Genomics to combat Resistance against Antibiotics in Community-acquired LRTI in Europe) consortium leading to these results was funded by the European Community's Sixth Framework Programme under grant agreement no. 518226. The work in the United Kingdom was also supported by the National Institute for Health Research (NIHR) (service support costs) and by the Research Foundation-Flanders (G.0274.08N). Orion Diagnostica supplied all the equipment and consumables for CRP testing.

The work reported as part of the final follow-up was also supported through the European Science Foundation (ESF), in the framework of the Research Networking Programme TRACE (www.esf.org/trace). Contributors to this programme: Bond University (Australia); Research Foundation-Flanders, University of Antwerp, University of Ghent (Belgium); Chinese University of Hong Kong (China); University of Copenhagen (Denmark); Research Council of Health, Academy of Finland (Finland); College Azuréen des Généralistes Enseignants, Comité Départemental d'Education pour la Santé (France); Rostock University (Germany); The Netherlands Organisation for Scientific Research, AMC Amsterdam, Leiden UMC, UMC Utrecht (The Netherlands); Research Council of Norway, University of Oslo, University of Tromso (Norway); Medical University of Bialystok, Medical University of Lodz (Poland); National University Research Council (Romania); Osnovno zdravstvo Gorenjske (Slovenia); I'Institut d'Investigacions Biomèdiques August Pi i Sunyer (Spain); Swedish Research Council, Karolinska Institute (Sweden); Medical Research Council, Cardiff University, University of Oxford, University of Southampton (United Kingdom); Swiss National Science Foundation (Switzerland).

Disclaimer: The funders and sponsor (University of Southampton) had no role in the management, analysis, interpretation or write-up of this project. The principal investigator (P.L.) made the decision to submit for publication following agreement from all authors. 


\section{Trial Registration: ISRCTN99871214}

Acknowledgments: We are grateful to members of the GRACE consortium trial team whose hard work has made this possible. We are very grateful to the clinicians and patients who consented to be part of GRACE, without whom this study would not have been possible. We also thank the independent GRACE trial steering committee (Patrick Bindels, Gordon Taylor, and Mark Woodhead) for their help and suggestions. The trial steering committee also supervised safety aspects of the trial as there was no independent data safety monitoring board (following similar precedents with low-risk MRC-funded trials, as the study was considered to be low risk). We are grateful to Orion Diagnostica for supplying all CRP materials.

- Supplementary materials: Available at http://www.AnnFamMed. org/content/17/2/125/suppl/DC1/.

\section{References}

1. Akkerman AE, van der Wouden JC, Kuyvenhoven MM, Dieleman JP, Verheij TJ. Antibiotic prescribing for respiratory tract infections in Dutch primary care in relation to patient age and clinical entities. J Antimicrob Chemother. 2004;54(6):1116-1121.

2. Petersen I, Johnson A, Islam A, et al. Protective effect of antibiotics against serious complications of common respiratory tract infections: retrospective cohort study with the UK General Practice Research Database. BMJ. 2007;335(7627):982.

3. Kroening-Roche JC, Soroudi A, Castillo EM, Vilke GM. Antibiotic and bronchodilator prescribing for acute bronchitis in the emergency department. J Emerg Med. 2012;43(2):221-227.

4. Butler CC, Hood K, Verheij T, et al. Variation in antibiotic prescribing and its impact on recovery in patients with acute cough in primary care: prospective study in 13 countries. BMJ. 2009;338:b2242.

5. Smith S, Fahey T, Smucny J, Becker LA. Antibiotics for acute bronchitis. Cochrane Database Syst Rev. 2014;1(3):CD000245.

6. Little P, Stuart B, Moore M, et al. Amoxicillin for acute lowerrespiratory-tract infection in primary care when pneumonia is not suspected: a 12-country, randomised, placebo-controlled trial. Lancet Infect Dis. 2013;13(2):123-129.

7. Goossens H, Ferech M, Vander Stichele R, Elseviers M; ESAC Project Group. Outpatient antibiotic use in Europe and association with resistance: a cross-national database study. Lancet. 2005;365(9459): 579-587.

8. Cals JW, Butler CC, Hopstaken RM, Hood K, Dinant GJ. Effect of point of care testing for $C$ reactive protein and training in communication skills on antibiotic use in lower respiratory tract infections: cluster randomised trial. BMJ. 2009;338:b1374.

9. Cals JW, Schot MJ, de Jong SA, Dinant GJ, Hopstaken RM. Point-ofcare C-reactive protein testing and antibiotic prescribing for respiratory tract infections: a randomized controlled trial. Ann Fam Med. 2010;8(2):124-133.

10. Arnold SR, Straus SE. Interventions to improve antibiotic prescribing practices in ambulatory care. Cochrane Database Syst Rev. 2005; (4):CD003539.

11. O'Brien MA, Rogers S, Jamtvedt G, et al. Educational outreach visits: effects on professional practice and health care outcomes. Cochrane Database Syst Rev. 2007;(4):CD000409.

12. van der Velden A, Pijpers $E$, Kuyvenhoven M, et al. Effectiveness of physician-targeted interventions to improve antibiotic use for respiratory tract infections. Br J Gen Pract. 2012;62:e801-e07(7).

13. Butler CC, Simpson SA, Dunstan F, et al. Effectiveness of multifaceted educational programme to reduce antibiotic dispensing in primary care: practice based randomised controlled trial. BMJ. 2012; 344:d8173.

14. Kumar S, Little P, Britten N. Why do general practitioners prescribe antibiotics for sore throat? A grounded theory interview study of general practitioners. BMJ. 2003;326:(7381):138.
15. Cornford CS. Why patients consult when they cough: a comparison of consulting and non-consulting patients. Br J Gen Pract. 1998; 48(436):1751-1754.

16. Minnaard MC, de Groot JA, Hopstaken RM, et al. The added value of C-reactive protein measurement in diagnosing pneumonia in primary care: a meta-analysis of individual patient data. CMAJ. 2017; 189(2):E56-E63.

17. National Institute for Health and Care Excellence (NICE). Pneumonia in Adults: Diagnosis and Management. London, UK: NICE; 2014. Clinical guideline 191.

18. Verheij T, Hopstaken R, Prince JM. Dutch College of General Practitioners Guidelines on Acute Cough 2011, updated 2013 [in Dutch]. Huisarts Wet. 2011;54(2):68-92.

19. Woodhead M, Blasi F, Ewig S, et al; Joint Taskforce of the European Respiratory Society and European Society for Clinical Microbiology and Infectious Diseases. Guidelines for the management of adult lower respiratory tract infections-full version. Clin Microbiol Infect. 2011;17(Suppl 6):E1-E59.

20. Little P, Stuart B, Francis N, et al; GRACE consortium. Effects of Internet-based training on antibiotic prescribing rates for acute respiratory-tract infections: a multinational, cluster, randomised, factorial, controlled trial. Lancet. 2013;382(9899):1175-1182.

21. Oppong R, Smith RD, Little $P$, et al. Cost-effectiveness of internetbased training for primary care clinicians on antibiotic prescribing for acute respiratory tract infections in Europe. J Antimicrob Chemother. 2018;73(11):3189-3198.

22. Anthierens S, Tonkin-Crine S, Douglas E, et al; GRACE INTRO study team. General practitioners' views on the acceptability and applicability of a web-based intervention to reduce antibiotic prescribing for acute cough in multiple European countries: a qualitative study prior to a randomised trial. BMC Fam Pract. 2012;13:101.

23. Francis NA, Butler CC, Hood K, Simpson S, Wood F, Nuttall J. Effect of using an interactive booklet about childhood respiratory tract infections in primary care consultations on reconsulting and antibiotic prescribing: a cluster randomised controlled trial. BMJ. 2009; 339:b2885.

24. Coenen S, Van Royen P, Michiels B, et al. Optimizing antibiotic prescribing for acute cough in general practice: a cluster-randomized controlled trial. J Antimicrob Chemother. 2004;54(3):661-672.

25. Welschen I, Kuyvenhoven M, Hoes A, et al. Effectiveness of a multiple intervention to reduce antibiotic prescribing for respiratory tract symptoms in primary care: randomised controlled trial. BMJ. 2004;329:431.

26. Adams G, Gulliford M, Ukoumunne O, et al. Patterns of intra-cluster correlation from primary care research to inform study design and analysis. J Clin Epidemiol. 2004;57(8):785-794.

27. Zhang J, Yu KF. What's the relative risk? A method of correcting the odds ratio in cohort studies of common outcomes. JAMA. 1998; 280(19):1690-1691.

28. Little P, Williamson I, Warner G, Gould C, Gantley M, Kinmonth AL. Open randomised trial of prescribing strategies in managing sore throat. BMJ. 1997;314(7082):722-727.

29. Little P, Gould C, Williamson I, Moore M, Warner G, Dunleavey J. Pragmatic randomised controlled trial of two prescribing strategies for childhood acute otitis media. BMJ. 2001;322(7282):336-342.

30. Yardley L, Douglas E, Anthierens S, et al; GRACE consortium. Evaluation of a web-based intervention to reduce antibiotic prescribing for LRTI in six European countries: quantitative process analysis of the GRACE/INTRO randomised controlled trial. Implement Sci. 2013;8:134.

31. Anthierens S, Tonkin-Crine S, Cals J, et al. Clinicians' views and experiences of interventions to enhance the quality of antibiotic prescribing for acute respiratory tract infections. J Gen Intern Med. 2015;30(4):408-416.

32. Cals JW, De Bock L, Beckers PJ, et al. Enhanced communication skills and C-reactive protein point-of-care testing for respiratory tract infection: 3.5-year followup of a cluster randomized trial. Ann Fam Med. 2013;11(2):157-164. 